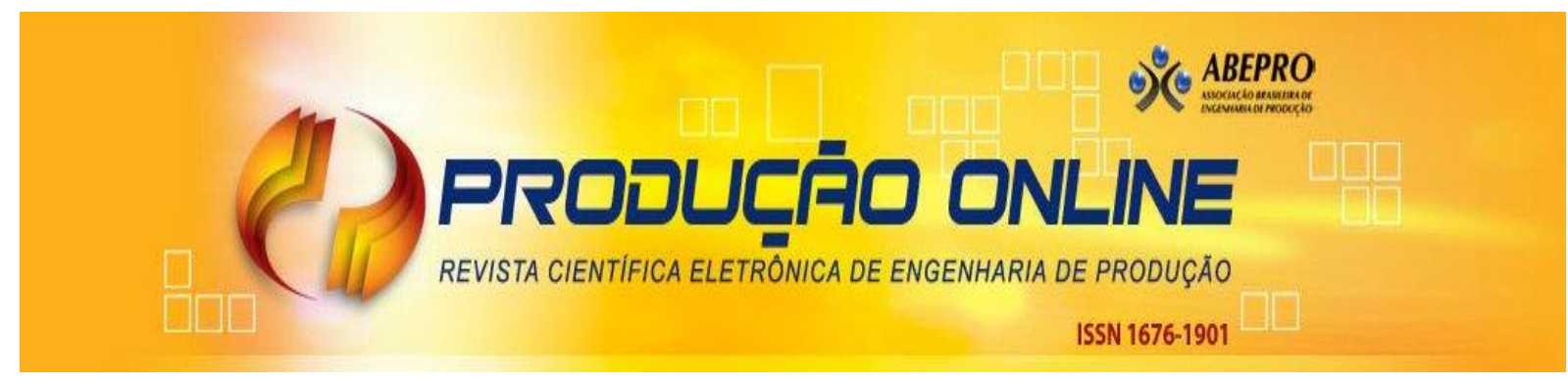

\title{
MAPEAMENTO DO FLUXO DE VALOR: ESTUDO DE CASO NA FABRICAÇÃO DE PRODUTOS PET FOOD
}

\section{VALUE STREAM MAPPING: CASE STUDY IN THE MANUFACTURE OF PET FOOD PRODUCTS}

\author{
Débora Bianco*E-mail: debora.unifei@gmail.com \\ Júlio Cesar dos Santos Junior* E-mail: juliocesar junior@hotmail.com \\ Juliana Keiko Sagawa* E-mail: j.keiko.sagawa@gmail.com \\ Moacir Godinho *E-mail: moacir@dep.ufscar.br \\ *Universidade Federal de São Carlos (UFSCAR), São Carlos, SP
}

Resumo: A metodologia lean tem sido implementada nas organizações para otimizar processos e diminuir os desperdícios, assim eleva a competitividade perante a concorrência e a performance da mesma. Para manter a fabricação enxuta, diversas ferramentas podem ser implementadas na organização, sendo uma delas o mapeamento do fluxo de valor (MFV). Desta forma, o presente estudo tem como propósito mapear o fluxo de valor da fabricação de produtos extrusados pet foode identificar os desperdícios para propor melhorias. O método de pesquisa utilizado foi o estudo de caso, que permitiu a análise aprofundada do processo produtivo em uma organização de grande porte. Com a aplicação do MFV obteve-se como resultado o mapa do estado atual e após a análise o mapa do estado futuro. As sugestões de melhoria incluíram sincronizar a produção ao adotar o Kanban e supermercados para introduzir o fluxo puxado de produção. Por fim, houve a redução do lead time de 13,8 dias para 6,13 dias e a quantidade de operadores de 17 para 12. A partir do estudo realizado, pode-se identificar lacunas para pesquisas futuras.

Palavras-chave: Produção enxuta. Mapeamento do fluxo de valor (MVF). Estudo de caso. Lean Manufacturing. Desperdícios.

\begin{abstract}
Lean methodology has been implemented in organizations to improve processes and reduce waste, thus improving competitiveness and performance. In order to maintain lean manufacturing, several tools can be implemented in the organization, one of them being Value Stream Mapping (VSM). Thus, the present study aims to map the flow of value of the manufacture of extruded pet food products, thus identifying the wastes inherent to the same and proposing improvements. The research method used was the case study, which allowed the in-depth analysis of the productive process in a large organization. With the application of the VSM we obtained as a result the map of the current state and after the analysis the map of the future state. Suggestions for improvement included synchronizing production while adopting Kanban and supermarkets to introduce the pulled production flow. Finally, there was a reduction of lead time to 13,8 days for 6.13 days and the number of operators to 17 for 12 . From the study, one can identify gaps for future research.
\end{abstract}

Keywords: Lean production. Lean Manufacturing. Value stream mapping (VSM). Case study. Waste. 


\section{INTRODUÇÃO}

A otimização dos processos de uma organização é possível a partir da análise dos desperdícios que ocorrem no chão de fábrica. As decisões da liderança devem ser baseadas, sempre que possível, no local de trabalho. É preciso que o líder visite o chão de fábrica e adquira conhecimento sobre o processo para que as soluções propostas sejam funcionais (LIKER; CONVIS, 2012). Uma das ferramentas do lean manufacturing, que pode ser utilizada com esse propósito, é o mapeamento do fluxo de valor (MFV), que permite a identificação dos desperdícios do processo. Para aplicala, o líder e o pesquisador percorrem todo o processo produtivo, da expedição final ao recebimento de matéria prima. Desta forma, as propostas de melhoria tornam-se mais efetivas pois são baseadas em fatos observados e relatados no chão de fábrica (ROTHER; SHOOK, 2003).

A literatura mostra que o MFV é uma ferramenta que auxilia a implantação do lean em diversos setores. Como no setor calçadista em que Lima et. al (2016) utilizam o MFV junto com a simulação para propor melhorias a uma organização; Singh, Garg e Sharma (2010) aplicaram a ferramenta para identificação de desperdícios na fabricação de componentes usados para a manutenção de máquinas ferroviárias; Hedlund e Forcellini (2018), realizaram a avaliação do desempenho energético em consumidores industriais com auxílio do MFV. O presente estudo, busca suprir a lacuna da literatura ao apresentar um exemplo prático da aplicação da ferramenta em uma organização de grande porte atuante no mercado pet, o qual tem ganhado espaço na economia mundial.

Segundo a Associação Brasileira da Indústria de Produtos para Animais de Estimação (Abinpet), em 2017, o faturamento do mercado pet mundial foi de US\$119,5 bilhões. Representou um crescimento de 13\% em relação ao ano de 2016. O Brasil é o quarto maior do mundo em população de animais de estimação. Os dados divulgados mostram o constante avanço do setor pet no mercado mundial, o que justifica a realização de pesquisas voltadas para a otimização dos processos industriais de organizações que atuam nesse mercado.

Diante de tais argumentos, o presente estudo se propõe a responder a seguinte questão: Quais as principais fontes de desperdícios no processo de fabricação de ração em uma indústria de grande porte? Sendo assim, o objetivo da pesquisa é 
identificar as fontes de desperdícios no processo de fabricação de ração por meio do mapeamento do fluxo de valor da família de produtos extrusados (Pet Food). A partir da análise do mapa atual, propor melhorias com a elaboração do mapeamento do fluxo de valor do estado futuro da organização.

Para atingir o objetivo proposto o presente artigo foi estruturado da seguinte forma: na seção 2 será apresentada a síntese do marco teórico (dividido em filosofia lean e mapeamento do fluxo de valor); na seção 3 o método de pesquisa (dividido em unidade de análise, mapa do estado atual e mapa do estado futuro); na seção 4 os resultados e discussões; na seção 5 as considerações finais e oportunidades de pesquisas futuras; por fim, serão apresentadas as referencias bibliográficas.

\section{SÍNTESE DO MARCO TEÓRICO}

\subsection{Filosofia Lean}

A filosofia do lean manufacturing surgiu a partir da teoria Just-in-time que foi desenvolvida para Toyota Motor Corporation e implementada no ano de 1970, com o objetivo de eliminar todos os elementos desnecessários na área de produção. Desta forma, os pilares dessa filosofia foram a redução de espaço e a eliminação de todos os desperdícios (GARCÍA; MALDONADO, 2016). Segundo Ohno (1997), cada processo deve receber $\mathrm{O}$ item exato necessário, quando for necessário e na quantidade exata requerida, sendo assim, a organização que estabelecer o fluxo dessa forma pode chegar ao estoque zero.

O Sistema Toyota de produção é o que define a administração da organização e Liker (2005) cita que pode ser implantado em qualquer companhia para otimizar os processos. Sejam esses de vendas, marketing, desenvolvimento de produtos, administração, logística ou qualquer outro que julgar necessário. Para auxiliar a liderança lean na implantação do pensamento enxuto, foi elaborado o "4Ps" do modelo Toyota: solução de problemas, equipe e parceiros, processo e filosofia.

Com a implementação da produção lean, os gerentes mudaram de postura. Eles deixaram o antigo papel de controle ou monitoramento de processos a partir dos escritórios e interação com funcionários apenas quando houvessem problemas. A medida que as melhorias foram incorporadas, os líderes passaram a frequentar o chão de fábrica e a desenvolver uma relação próxima com seus subordinados. O seu 
principal papel tornou-se apoiar os funcionários. Desta forma, o desenvolvimento e valorização das pessoas passou a ganhar importância para torná-las motivadas e empenhadas a resolver problemas. O líder reconheceu que seu papel é ser facilitador e fornecer treinamentos e não apenas controlador (POKSINSKA; SWARTLING; DROTZ, 2013).

A solução de problemas envolve a aprendizagem organizacional contínua por meio do Kaizen. Tomar decisões lentamente com consenso, considerar todas as opções e implementá-las com rapidez. Quanto aos funcionários e parceiros, devem ser respeitados, desafiados sempre que necessário e desenvolvidos constantemente, além de treinar líderes que vivenciem a filosofia. Para os processos, o foco deve ser eliminar todos os desperdícios e com esse intuito deve-se utilizar o sistema puxado para evitar a superprodução, praticar a melhoria contínua, realizar a gestão a vista. Quanto a filosofia, o pensamento deve ser a longo prazo, mesmo em detrimento a metas financeiras de curto prazo (LIKER, 2005).

A Toyota identificou sete tipos de desperdícios que são aplicáveis em diversas operações como manufatura e serviços. A metodologia lean apresenta diversas ferramentas com o objetivo de eliminar esses desperdícios que serão citados a seguir (OHNO, 1997): superprodução, o que consta em produzir mais do que o necessário para o próximo processo da produção; tempo disponível (espera), que é medido a partir da eficiência de máquina e de mão de obra além do tempo de espera de materiais; transporte, desperdícios devido à movimentação de materiais dentro da fábrica assim como a movimentação de estoques; processo, em que algumas operações existem apenas em função do projeto ruim de componentes ou manutenção ruim que podem ser eliminados; estoque, todo o estoque deve ser eliminado, contudo é necessário que sejam descobertas as causas do mesmo; movimentação, o trabalho deve ser simplificado para auxiliar na diminuição desse tipo de desperdício; produtos defeituosos, os desperdícios com qualidade são muito significativos em operações e devem ser eliminados para evitar retrabalho.

O lead time (tempo de atravessamento considerado desde a ordem de fabricação até entrega do produto final) tem sido um ponto critico para as organizações que buscam se manter no mercado de forma competitiva. Uma vez que todos os competidores possuem acesso as novas tecnologias de produção e as novas informações do mercado ao mesmo tempo, é necessário buscar novas formas de 
atender ao cliente sem depender desses recursos. Lidera o mercado aquele que consegue realizar a entrega em curto prazo, alcançando altas taxas de produção, alto nível de qualidade, o que permite a troca de informações com o mercado e o processo produtivo (WARD, SOBEC; 2014).

\subsection{Mapeamento do fluxo de valor}

A gestão do fluxo de valor envolve o processo de mensurar, entender e melhorar o fluxo e interação de todos os membros do processo. Assim, manter o custo, serviço e qualidade dos produtos e serviços da organização o mais competitivo possível. O mapeamento do fluxo de valor é utilizado como ferramenta para identificar oportunidades, agregar valor, eliminar os desperdícios e otimizar o fluxo (KEYTE; LOCHER, 2004).

O MFV é diferente de outras técnicas convencionais, pois permite a visualização das informações correspondentes a cada uma das estações individuais de trabalho. Expõe o tempo de ciclo do posto de trabalho, a utilização dos recursos, tempos de set-up, estoques em processo, quantidade de operários e o fluxo de informações desde o estoque de matéria prima até o produto acabado (SINGH; GARG; SHARMA, 2010). É possível visualizar o caminho da "produção" de um item ou serviço, do início ao fim, além de constar o fluxo de informação do processo. Esse é o começo da jornada da gestão do fluxo de valor e a ferramenta que irá estabelecer a direção e o foco da transformação lean (KEYTE; LOCHER, 2004).

Para o sucesso da gestão do fluxo de valor Keyte e Locher (2004) relatam a importância de que a alta gerência identifique a necessidade de mudança e conduza o processo de forma estratégica. Deve-se selecionar um gestor para cada um dos fluxos de valor. A comunicação com a alta gerência deve ser constante, para manter o foco nas operações estratégicas e aplicação das ferramentas do lean na organização. É essencial o entendimento e suporte das bases da estratégia lean em todos os níveis da organização. Aderir as métricas e comportamentos lean na criação de valor, eliminação de desperdício e monitorar o curso financeiro e operacional para o sucesso estratégico. Por fim, é importante que o mapa do estado futuro seja implantado na organização. 
A justificativa para o uso da ferramenta é auxiliar pesquisadores ou profissionais a identificar o desperdício em fluxos de valor individuais, assim encontrar um caminho apropriado para a remoção ou redução desses resíduos. O mapeamento possibilita a análise do processo para a identificação daqueles que não agregam valor (NAV), os que não agregam valor mas são necessários (NNAV) e os que agregam valor (AV) (HINES; RICH, 1997).

O primeiro (NAV) refere-se a um desperdício real e envolve ações desnecessárias que devem ser eliminadas completamente (como o tempo de espera, estoques intermediários, retrabalho). As NNAV podem ser um desperdício, mas são necessárias de acordo com os procedimentos operacionais atuais (como caminhar longas distâncias para troca de ferramentas; transferência de ferramenta; movimentação do operário). Para eliminar essas operações, seriam necessárias grandes alterações no sistema operacional, como a criação de um novo layout. Operações de valor agregado envolvem a conversão ou processamento de matériasprimas ou produtos semiacabados através do uso de mão de obra (HINES e RICH, 1997).

Mapas de fluxo de valor são criados por equipes multifuncionais, abrangendo os envolvidos no processo em consideração. As simbologias para o mapeamento é de escolha do pesquisador, as utilizadas no presente estudo encontram-se no quadro 1. Existem dois tipos de mapas de fluxo de valor: "estado atual" (como pode ser observado na figura 3) e "estado futuro" (como pode ser observado na figura 5). 0 primeiro descreve a maneira atual como o material e as informações são processados. Pode-se notar que gerentes não estão cientes da grande quantidade de desperdício que existe em um processo, bem como a existência de sinais confusos de informação até que o mapa do estado atual seja desenhado (EMILIANI; STEC, 2004).

Mapas de fluxo de valor de estado futuro descrevem uma condição futura que incorpora melhorias ainda a serem feitas. A equipe, com o auxílio de um facilitador experiente, identifica as melhorias ao questionar os paradigmas atuais e pensando com criatividade sobre como melhorar o processo. Às vezes, um mapa de fluxo de valor de "estado ideal" será desenhado para orientar futuras atividades de melhoria contínua. Os mapas do fluxo de valor devem ser apresentados à gerência sênior para revisão e aprovação (EMILIANI e STEC, 2004). 
Contudo, após desenhar o fluxo de valor do estado atual da organização, devese analisá-lo e então redesenhar o fluxo para estabelecer o mapa do estado futuro. $O$ mapa do estado futuro deve ser elaborado considerando a filosofia enxuta ao estabelecer um procedimento para fazer somente o que o próximo processo necessita e quando necessita. Assim, toda a cadeia de suprimentos é conectada, deste o consumidor final até a matéria prima, em um fluxo regular sem retornos que gere $o$ menor "lead time", a mais alta qualidade e o custo mais baixo. A melhoria contínua é colocada em prática sempre que o mapa for redesenhado, esse ciclo pode ser observado na figura 1 ( ROTHER; SHOOK, 2003).

Figura 1 - Ciclo de melhoria contínua

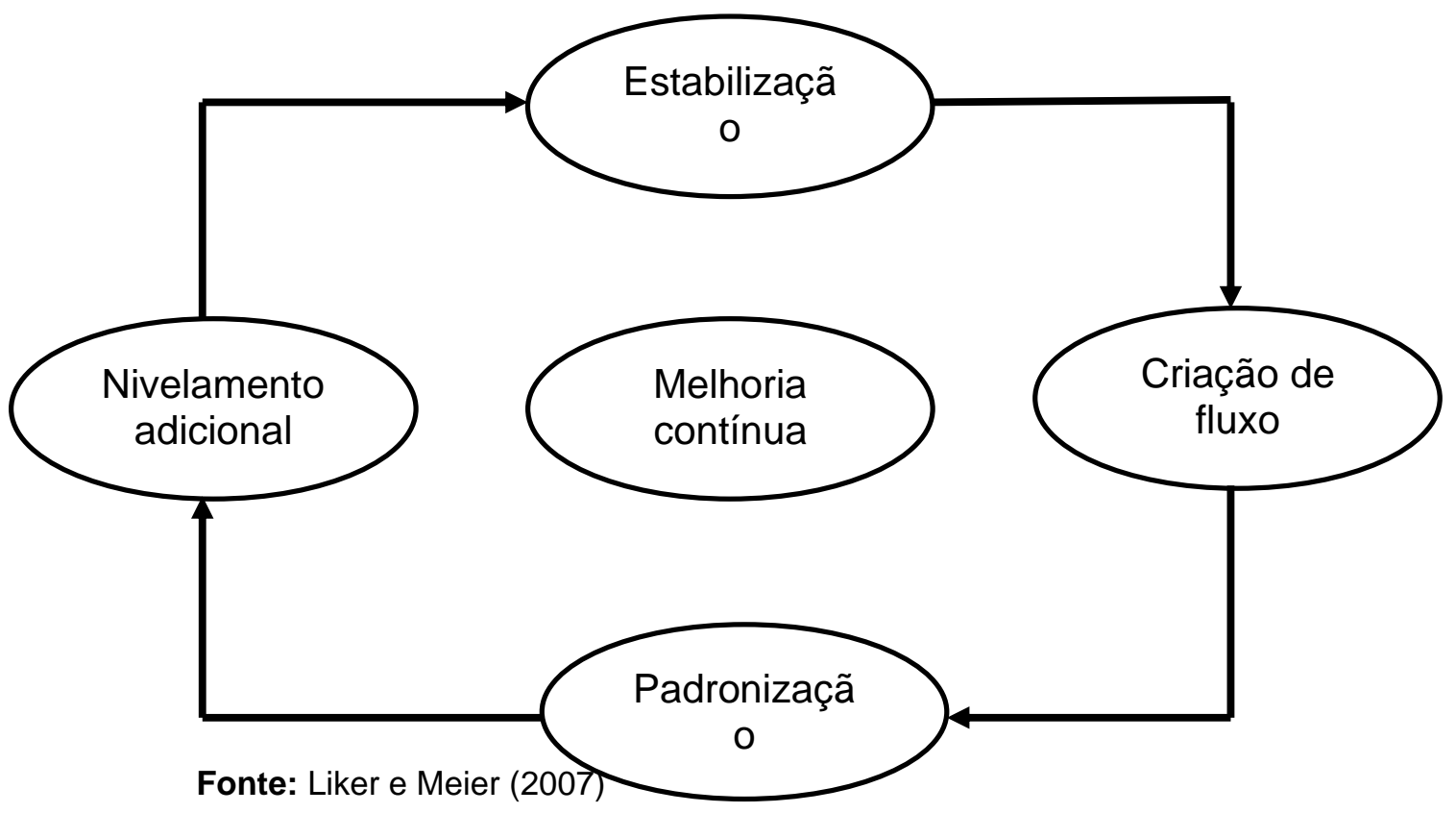

Segundo a revisão da literatura realizada por Forno et. al (2014), quando não aplicado corretamente, o MFV pode complicar a identificação de resíduos, levar a interpretações errôneas e a erros de avaliação, além de prejudicar a implementação de melhorias futuras. Os autores relatam a importância do sistema de medição e coleta de dados para garantir a confiabilidade e possibilitar a replicação do projeto. Entre as principais dificuldades está o tempo gasto na coleta dos dados para a construção do mapa do estado atual, impedindo a utilização contínua da ferramenta pela organização. Sendo assim, facilitar esse processo pode criar oportunidades para aplicar o MFV com frequência, tornando a ferramenta mais útil em processos de melhoria contínua (kaizen). As medições contínuas de dados podem levar à adoção 
de métodos estatísticos para monitorar o desempenho dos processos e os resultados dos mapas de estado futuros. O mapeamento do fluxo de valor realizado no presente estudo seguiu a simbologia apresentada no quadro 1.

Quadro 1 - Ícones utilizados no MFV

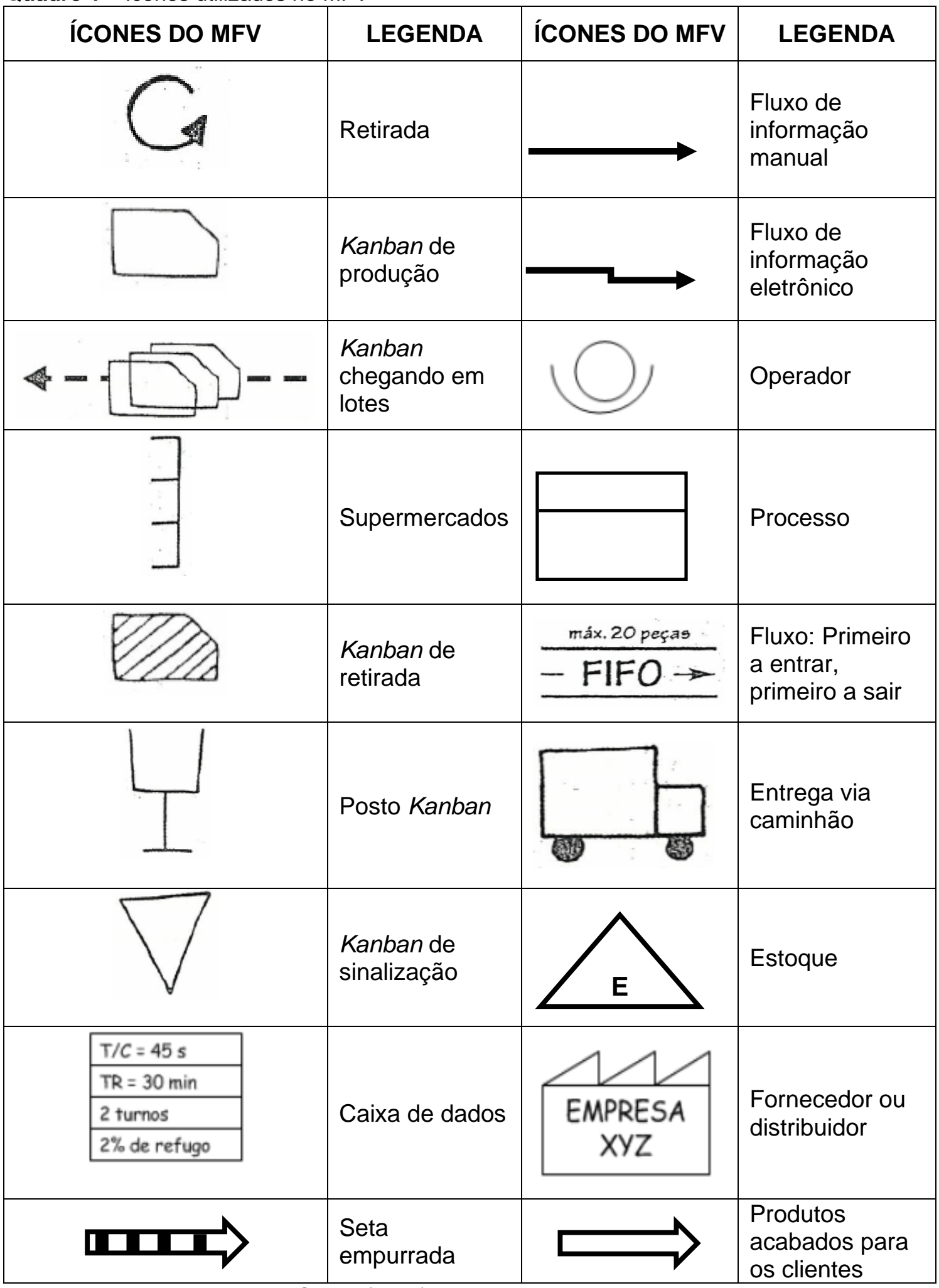

Fonte: Adaptado de Rother e Shook (2003)

Revista Produção Online. Florianópolis, SC, v. 19, n. 4, p. 1345-1368, 2019 


\section{MÉTODO DE PESQUISA}

Com a finalidade de atingir os objetivos do presente estudo, foi realizada uma pesquisa exploratória com abordagem qualitativa. Com relação à abordagem, Pizzinatto e Farah (2012) afirmam que uma pesquisa qualitativa privilegia a obtenção de dados não quantitativos em profundidade sobre determinado tema de interesse e a busca de resultados a partir deles sem a pretensão de usar procedimentos estatísticos para sua análise. Quanto à pesquisa exploratória, Gil (2002), determina que o objetivo principal é o aprimoramento de ideias ou descoberta de intuições, de forma flexível, o que possibilita a consideração dos mais variáveis aspectos relativos ao fato estudado.

O método de pesquisa adotado foi o estudo de caso e seguiu os passos propostos por Cauchick et al. (2009). Os primeiros passos são definir uma estrutura conceitual teórica, mapear a literatura, delimitar as fronteiras da pesquisa e delinear as proposições. Em seguida é necessário planejar os casos, definir as unidades de análise, meios para coleta de dados e controle da pesquisa para possibilitar a condução do teste piloto. Então, deve-se realizar a coleta e análise dos dados, com construção de painéis e identificar as causalidades. Por fim, gera-se relatórios para possibilitar a replicação da pesquisa.

\subsection{Unidade de análise}

O mapeamento do fluxo de valor foi aplicado em uma indústria do setor de alimentos para animais localizada no interior de São Paulo e pode ser considerada de grande porte devido ao volume de produção e número de funcionários. A empresa pertence a um grupo francês, que está presente em 28 países, com 73 fábricas, totalizando 7.700 empregados. O grupo está no ranking das organizações mais importantes do segmento no mundo.

No Brasil, o grupo possui 13 fábricas e emprega 2.400 funcionários. A sua história no Brasil começou em 1940 e nos últimos anos teve aquisições de organizações muito importantes para a economia do país, totalizando 6 novas empresas na última década. A unidade em que foi realizada a pesquisa, possui 3 segmentos de fabricação: extrusão, peletizagem, e premix. 
O setor de extrusão é direcionado para a fabricação de produtos pet food, ou seja, cão e gato. O setor de peletizagem é voltado para a fabricação de produtos para grandes animais, como ruminantes e equinos. O setor de premix tem como foco produtos de eficiência energética, como suplementos alimentares e vitaminas. Com os 3 setores produtivos, a capacidade diária de produção da planta é de 500 toneladas. O setor de extrusão é o centro das atenções dos acionistas e investidores, pois é o de maior lucratividade e consequentemente o de melhor qualidade de equipamentos e tecnologias de automação. Devido a isso, foi escolhido como foco desse estudo. A descrição detalhada de cada um dos processo pertencentes a fabricação dos produtos extrusados (pet food) está apresentada no quadro 2.

Atualmente, os animais de estimação são tratados como crianças e recebem carinho de seus donos. É gasto um valor alto em pet shops, sendo que existem variedades de produtos para alimentação, saúde e higiene do animal. No passado era comum alimentar os cachorros com restos de comida, atualmente este cenário mudou. Os animais são alimentados por rações para ter uma vida saudável e ficar com boa aparência na pelagem, reduzir odor de fezes, entre outras vantagens.

De acordo com Mazon e Moura (2016), estudos mostram resultados interessantes em relação ao segmento. O IBGE revela que é maior o número de lares com cachorros do que com crianças. As estimativas do lbope dizem que 59\% dos domicílios brasileiros tem algum animal de estimação, $44 \%$ deles há pelo menos um cão, e 16\% um gato. Esse estudo também diz que é gasto aproximadamente 340 reais por ano, para manter um único animal. Porém, esse valor pode aumentar de acordo com a qualidade dos produtos a serem oferecidos ao animal. $O$ faturamento deste setor no mercado está em torno de 16 milhões de reais.

Segundo Gates (2008), a indústria pet food é uma invenção recente. Ela surgiu em $1860 \mathrm{com}$ a primeira invenção de um biscoito canino, feita por James Spratt ao ver cachorros comendo biscoitos em uma lata de lixo em Londres. Então, surgiram métodos de fabricação para o aperfeiçoamento do biscoito canino. O processo de extrusão foi inventado 1950. Para a extrusão é necessário o cozimento do produto com adição de água e vapor, expandindo o produto em altas temperaturas e também com presença de força mecânica. Essa tecnologia permite maior durabilidade do produto, sendo a de maior sucesso até os dias atuais. 


\begin{tabular}{|c|c|c|}
\hline PROCESSO & DESPERDÍCIOS & ANÁLISE \\
\hline Recebimento & $\begin{array}{l}\text {-Excesso de } \\
\text { funcionários; } \\
\text {-Elevado estoque } \\
\text { de matéria prima. }\end{array}$ & $\begin{array}{l}\text { O processo de recebimento da matéria prima é } \\
\text { realizado por } 3 \text { funcionários. Eles são responsáveis } \\
\text { por descarregar os caminhões e alocar os produtos } \\
\text { no estoque inicial de forma organizada. O tempo } \\
\text { decorrido nessa atividade é de } 1,5 \text { horas. } 500 \\
\text { toneladas de matéria prima fica acumulada no } \\
\text { estoque inicial por } 3 \text { dias. Observa-se que } \\
\text { considerando um turno de } 8 \text { horas os funcionários } \\
\text { passam tempo ocioso, sendo possível que os } \\
\text { mesmos funcionários que trabalham na expedição } \\
\text { realizem o recebimento de mercadorias. A } \\
\text { disponibilidade é de } 88 \% \text {, pois o processo não é } \\
\text { automatizado, então é descontado o tempo de } \\
\text { almoço e descanso dos funcionários. }\end{array}$ \\
\hline Dosagem & $\begin{array}{l}\text {-Estoque entre } \\
\text { processos; } \\
\text {-Excesso de } \\
\text { funcionários; }\end{array}$ & $\begin{array}{l}\text { Para a dosagem, é retirado do estoque de matéria } \\
\text { prima os produtos nas quantidades especificadas } \\
\text { no procedimento de fabricação para a produção que } \\
\text { será iniciada. Os mesmos são alocados em um } \\
\text { recipiente. Essa atividade é realizada por dois } \\
\text { funcionários e demora } 6 \text { minutos. Porém, quando é } \\
\text { necessário realizar a limpeza do local para a troca } \\
\text { de produção é necessário } 2 \text { minutos adicionais. } \\
\text { Essa atividade seria mais eficiente se acontecesse } \\
\text { de forma continua e fosse agregada a outros } \\
\text { processos. A atividade gera um estoque entre } \\
\text { processos de } 3 \text { toneladas que ficam armazenadas } \\
\text { por } 2 \text { minutos. }\end{array}$ \\
\hline Mistura & $\begin{array}{l}\text {-Estoque entre } \\
\text { processos; }\end{array}$ & $\begin{array}{l}\text { No processo de mistura, os produtos que foram } \\
\text { dosados e separados anteriormente são misturados } \\
\text { durante } 1 \text { minuto e quando é necessário a limpeza } \\
\text { para a troca de produção mais } 1 \text { minuto é } \\
\text { adicionado. Apenas } 1 \text { funcionário realiza a } \\
\text { atividade, a qual seria mais eficiente se } \\
\text { acontecesse de forma contínua e fosse agregada a } \\
\text { outros processos. A atividade gera um estoque } \\
\text { entre processos de } 1,5 \text { toneladas que ficam } \\
\text { armazenadas durante } 1 \text { minuto. }\end{array}$ \\
\hline Moagem & $\begin{array}{l}\text {-Estoque entre } \\
\text { processos; }\end{array}$ & $\begin{array}{l}\text { Nesse processo ocorre a moagem para que o } \\
\text { produto se encontre na espessura ideal para o } \\
\text { processo de cozimento. Demora } 5 \text { minutos e } 2,5 \\
\text { minutos adicionais quando realiza-se a limpeza } \\
\text { para troca de produção. Apenas } 1 \text { funcionário } \\
\text { realiza a atividade e seria mais eficiente se } \\
\text { acontecesse de forma contínua e fosse agregada a } \\
\text { outros processos. A atividade gera um estoque } \\
\text { entre processos de } 40 \text { toneladas que ficam } \\
\text { armazenadas durante } 5 \text { horas. }\end{array}$ \\
\hline
\end{tabular}


Quadro 2 - Análise dos processos

(conclusão)

\begin{tabular}{|c|c|c|}
\hline PROCESSO & DESPERDÍCIOS & ANÁLISE \\
\hline $\begin{array}{l}\text { Cozimento / } \\
\text { Molde e corte/ } \\
\text { secagem }\end{array}$ & $\begin{array}{l}\text {-Elevado tempo } \\
\text { de troca; } \\
\text {-Estoque entre } \\
\text { processos. }\end{array}$ & $\begin{array}{l}\text { Os três processos ocorrem de forma contínua sem } \\
\text { paradas ou estoques entre eles. Apenas } 1 \\
\text { funcionário realiza a atividade e demora } 6,33 \\
\text { minutos, sendo necessário } 15 \text { minutos para as } \\
\text { trocas de produção. O estoque após o processo é } \\
\text { de } 3 \text { toneladas que ficam armazenadas por } 5 \\
\text { minutos. }\end{array}$ \\
\hline Resfriamento & $\begin{array}{l}\text {-Elevado tempo } \\
\text { de troca; } \\
\text {-Estoque entre } \\
\text { processos. }\end{array}$ & $\begin{array}{l}\text { O processo de resfriamento do produto leva } 5 \\
\text { minutos e para a troca da produção } 6 \text { minutos. É } \\
\text { necessário } 1 \text { funcionário na operação e o processo } \\
\text { gera } 2 \text { toneladas de estoque em processo que fica } \\
\text { armazenado durante } 6 \text { minutos. }\end{array}$ \\
\hline Engorduramento & $\begin{array}{l}\text {-Elevado tempo } \\
\text { de troca; } \\
\text {-Estoque entre } \\
\text { processos. }\end{array}$ & $\begin{array}{l}\text { O processo de engorduramento do produto leva } 5 \\
\text { minutos e para a troca da produção } 6 \text { minutos. É } \\
\text { necessário } 1 \text { funcionário na operação e o processo } \\
\text { gera } 80 \text { toneladas de estoque em processo que fica } \\
\text { armazenado durante } 12 \text { horas. }\end{array}$ \\
\hline Envase & $\begin{array}{l}\text {-Elevado estoque } \\
\text { de produto } \\
\text { acabado. }\end{array}$ & $\begin{array}{l}\text { Nesse processo o produto é devidamente } \\
\text { embalado. Para isso, são necessários } 2 \\
\text { funcionários e } 7 \text { minutos em operação. A troca de } \\
\text { produção demora } 10 \text { minutos. A disponibilidade é éto } \\
\text { de } 88 \% \text { pois o processo não é automatizado, então } \\
\text { é descontado o tempo de almoço e descanso dos } \\
\text { funcionários. Após o envase os produtos são } \\
\text { alocados no estoque de produto acabado, que } \\
\text { consta } 1500 \text { toneladas que ficam armazenadas } \\
\text { durante } 10 \text { dias. }\end{array}$ \\
\hline Expedição & $\begin{array}{l}\text {-Excesso de } \\
\text { funcionários. }\end{array}$ & $\begin{array}{l}\text { Nesse processo é realizada a retirada dos produtos } \\
\text { acabados do estoque final e o carregamento dos } \\
\text { caminhões. } 5 \text { funcionários são necessários e levam } \\
1,5 \text { horas nessa atividade. A troca de carregamento } \\
\text { demora } 10 \text { minutos. A disponibilidade é de } 88 \% \text { pois } \\
\text { o processo não é automatizado, então é descontado } \\
\text { o tempo de almoço e descanso dos funcionários. }\end{array}$ \\
\hline
\end{tabular}

Fonte: Elaborado pelos autores

\subsection{Mapa do estado atual}

Para realizar o mapa do estado atual, os passos propostos por Rother e Shook (2003) na figura 2 e os símbolos apresentados no quadro 1 foram seguidos. A coleta dos dados foi realizada pelo pesquisador ao caminhar por todo o fluxo de valor referente a família de produtos extrusados pet food. Começou-se pela expedição final, passando por todos os processos que agregam valor ao produto e também verificando 
os pontos de estocagem de componentes que não agregam valor e terminou o percurso no recebimento da matéria prima.

Figura 2 - Execução do mapa do estado atual

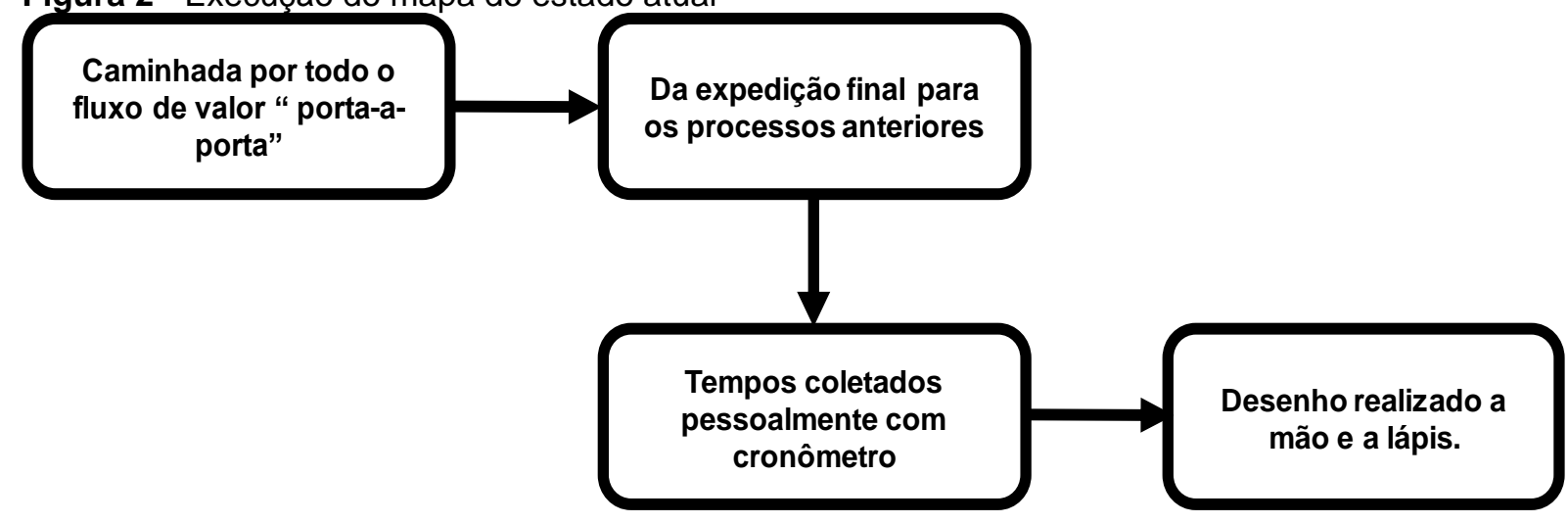

Fonte: Adaptado de Rother e Shook (2003)

As informações consideradas na coleta de cada um dos itens apresentados no mapeamento encontra-se no quadro 3. As coletas dos tempos de ciclo (TC), tempo de troca (TR) e disponibilidade foram realizadas com o auxílio de um cronômetro e podem ser observados nas caixas de informações contidas no mapa do estado atual logo abaixo de cada processo (figura 3). Na coleta do tempo de ciclo foi considerado o tempo (em segundos) que leva para que 1,5 toneladas de material (lote de produção) sejam processadas em cada uma das etapas de fabricação.

Para o tempo de troca, considerou-se os segundos necessários para realizar a limpeza dos equipamentos quando é realizada a troca do lote de produção $(1,5$ toneladas de material) e para o processo de molde e corte considerou-se também os segundos necessários para realizar a troca do disco. No cálculo da disponibilidade foi considerado o tempo de trabalho disponível por turno no processo e subtraíram-se os tempos de refeição e reunião com operadores. Os processos de recebimento envase e expedição possuem uma disponibilidade de $88 \%$, pois para eles foi descontado o tempo de almoço e descanso dos operadores. Os demais processos são realizados de forma automatizada atingindo uma disponibilidade de $100 \%$ referente aos turnos de trabalho.

A linha do tempo, encontra-se na parte inferior do mapa e é composta dos tempos de ciclo e dos tempos referentes a estocagem dos materiais. Pode-se observar que existem 8 pontos de estocagem de materiais ao decorrer do processo 
produtivo de produtos extrusados pet food. Os pontos de estocagem devem ser analisados com cuidado, pois podem representar desperdício de capital e atraso para a entrega do produto final. Esses pontos são processos que não agregam valor e alguns deles desnecessários, onde melhorias devem ser implementadas. Na caixa de informações ao final da linha do tempo pode-se observar o lead time (composto pela somatória dos tempos de ciclo e tempos em estoque) e o tempo de processamento composto apenas pela somatória dos tempos em processos que agregam valor ao produto.

$\mathrm{Na}$ parte superior do mapa encontra-se o fluxo de informação que ocorre de forma eletrônica. Em que o controle da produção envia a ordem de produção diária aos processos de recebimento, dosagem, envase e expedição. Além disso, o controle da produção realiza a previsão semanal ao entrar em contato com os fornecedores e recebe o pedido diário dos clientes (distribuidores).Considera-se a fabricação de 90 toneladas por turno (8 horas). O transporte tanto da matéria prima quanto do produto final aos centros de distribuição é realizado por caminhões e ocorre diariamente.

Quadro 3 - Variáveis consideradas no estudo

\begin{tabular}{|l|l|}
\hline \multicolumn{1}{|c|}{ VARIÁVEL } & \multicolumn{1}{|c|}{$\begin{array}{c}\text { ADAPTAÇÃO PARA O PRESENTE } \\
\text { ESTUDO }\end{array}$} \\
\hline Tempo de ciclo & $\begin{array}{l}\text { Foi cronometrado o tempo que leva entre } \\
\text { um componente entrar e sair do mesmo } \\
\text { processo. }\end{array}$ \\
\hline Tempo de troca & $\begin{array}{l}\text { Foi cronometrado o tempo dispendido para } \\
\text { as atividades de limpeza em todos os } \\
\text { processos e durante a moldagem a troca do } \\
\text { disco. }\end{array}$ \\
\hline Tempo de processamento & $\begin{array}{l}\text { Considerou-se apenas o tempo de } \\
\text { agregação de valor, ou seja, a somatória dos } \\
\text { tempos de ciclo. }\end{array}$ \\
\hline Lead time & $\begin{array}{l}\text { Considerou-se o tempo que um lote de } \\
\text { produção (1,5 toneladas) leva para mover-se } \\
\text { ao longo de todo o fluxo de valor. }\end{array}$ \\
\hline Disponibilidade & $\begin{array}{l}\text { Considerou-se o tempo de trabalho } \\
\text { disponível por turno no processo, subtraindo } \\
\text { os minutos de descanso e reuniões }\end{array}$ \\
\hline
\end{tabular}

Fonte: Elaborado pelos autores 
Fiqura 3- Mapa do estado atual

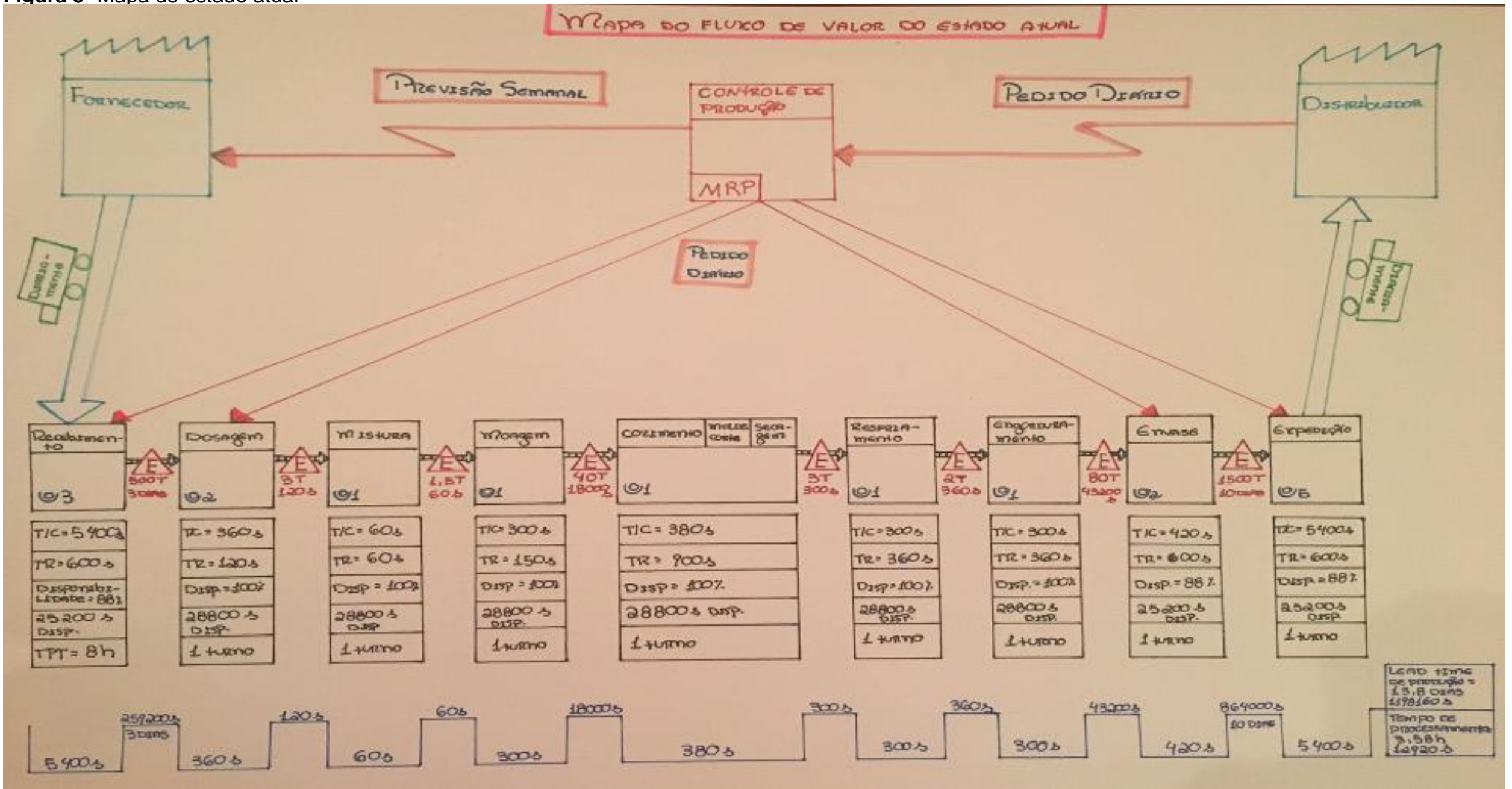

Fonte: Elaborado pelos autores 


\subsection{Mapa do estado futuro}

A partir da análise realizada do mapa do estado atual, foi possível elaborar o mapa do estado futuro o qual seguiu os passos propostos por Rother e Shook (2003) como pode ser observado na figura 4. O mapa futuro foi construído com a mesma simbologia apresentada na seção anterior referente ao mapa do estado atual (quadro 1). Contudo, foram adicionadas algumas melhorias que serão apresentadas a seguir.

Figura 4- Execução do mapa do estado futuro

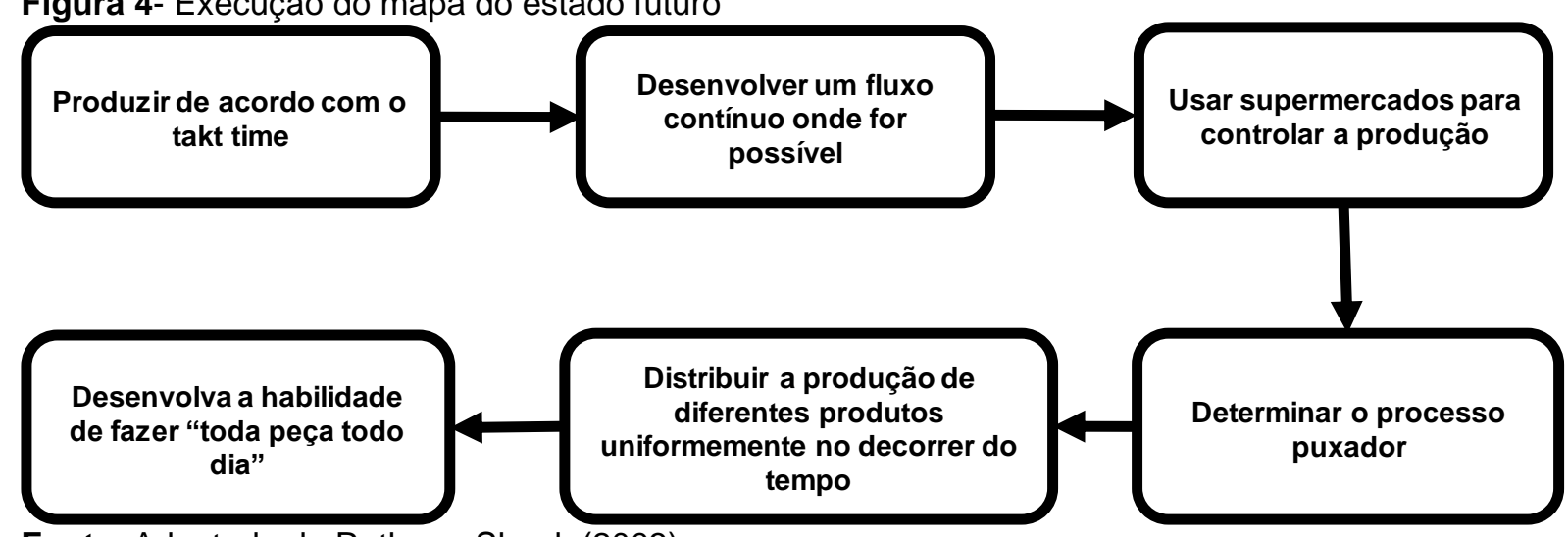

Fonte: Adaptado de Rother e Shook (2003)

Primeiro realizou-se uma análise aprofundada do processo produtivo junto com o supervisor para que as melhorias propostas no mapa do estado futuro (figura 5) fossem possíveis de se concretizar na prática. Todos os processos que poderiam ocorrer de forma contínua foram integrados em uma única célula de produção, como no caso da junção da dosagem, mistura e moagem. O cozimento, molde/corte, e secagem já ocorriam em fluxo contínuo mesmo no mapa do estado atual. A linha FIFO (com o máximo de ocupação referente a 1,5 toneladas) foi aplicada antes e após o processo de resfriamento, permitindo o fluxo contínuo de materiais entre os processos de secagem, resfriamento e engorduramento.

Segundo Emiliani (1998) o conceito de puxar na produção enxuta significa responder à demanda do cliente. As organizações enxutas projetam suas operações para responder às exigências, em constante mudança, dos clientes finais. Por outro lado, as demais organizações projetam as operações para atender às próprias necessidades locais. Aqueles capazes de produzir para atender aos consumidores finais não precisam fabricar produtos de acordo com previsões imprecisas, nas quais 
os fabricantes de lotes grandes e estocagem devem confiar. O planejamento para a entrega do produto aos consumidores é menos problemático e a demanda se torna mais estável. Pois, os clientes confiam que vão obter o que desejam e quando desejam.

Segundo Hammarberg e Sundén (2014) o sistema de coordenação de ordens Kanban pode ser utilizado para possibilitar a visualização do trabalho que deve ser executado. Expõe o fluxo de trabalho em um quadro e o processo real se torna aparente para todos da equipe. Além disso, esse sistema permite a limitação dos estoques em processo e diminuição do tamanho do lote para que cada componente seja processado de forma mais rápida. Por fim, os cartões Kanban auxiliam a gerenciar o fluxo produtivo de forma rápida sem que existam interrupções ao fluxo de trabalho.

O Kanban é um método de coordenação de ordens altamente eficiente em ambientes produtivos com baixa variedade de produtos e sistema de produção para estocagem (Make to Stock), como o caso apresentado no presente estudo (SILVA et al, 2017). Na produção Make to Stock os produtos são padronizados e fabricados de forma repetitiva, sem que o cliente participe de forma direta na definição do produto. Esse sistema tem como vantagem a rapidez na entrega dos produtos, porém os custos de estocagem podem ser altos (SAGAWA; DELAI; PEREIRA, 2015).

Sendo assim, para estabelecer um fluxo de produção puxado aplicou-se o sistema de coordenação de ordens Kanban e o processo de expedição foi definido como o "processo puxador" pois é o único que recebe do controle da produção (MRP) diariamente com as instruções para iniciar a fabricação. Os pontos de estocagem foram discutidos de forma cuidadosa com o supervisor de produção. O qual, definiu o mínimo necessário para não prejudicar a fabricação caso houvesse a quebra de algum equipamento, parada para manutenção, ou alguma falha imprevista.

Os estoques do mapa atual, foram substituídos por supermercados colocados em pontos estratégicos da linha produtiva. No supermercado de matéria prima é necessário a estocagem de 500 toneladas para que contratempos com o fornecedor não prejudiquem a produção. Quanto ao produto final, é necessário que exista um estoque de 450 toneladas para que o atendimento a demanda do cliente final seja garantida. A primeira célula de produção (dosagem, mistura e moagem) possui o tempo de ciclo igual a 720 segundos (que é maior do que o da próxima célula em fluxo 
contínuo). Sendo assim, pode ser considerada um gargalo e para não atrasar a produção foi necessário um supermercado após a mesma. Antes do processo de envase, foi necessário o supermercado para assegurar que possíveis falhas nos equipamentos anteriores não interfira no empacotamento e finalização do produto.

Contudo, o fluxo puxado de produção ocorre da seguinte forma: O controle de produção (MRP) envia a ordem de fabricação para a expedição. A expedição, realiza a retirada no supermercado de produtos acabados, acionando o Kanban de produção para o processo de envase. O envase, ao realizar a retirada no supermercado, aciona o Kanban de produção para o processo de cozimento. O processo de cozimento ao realizar a retirada de material do supermercado aciona o Kanban de produção para o processo de dosagem. $O$ processo de dosagem fará a retirada no supermercado de matéria prima acionando o Kanban de sinalização para o controle da produção. Por fim, é realizado o pedido ao fornecedor para que todo o sistema seja reabastecido. 
Figura 5- Mapa do estado futuro

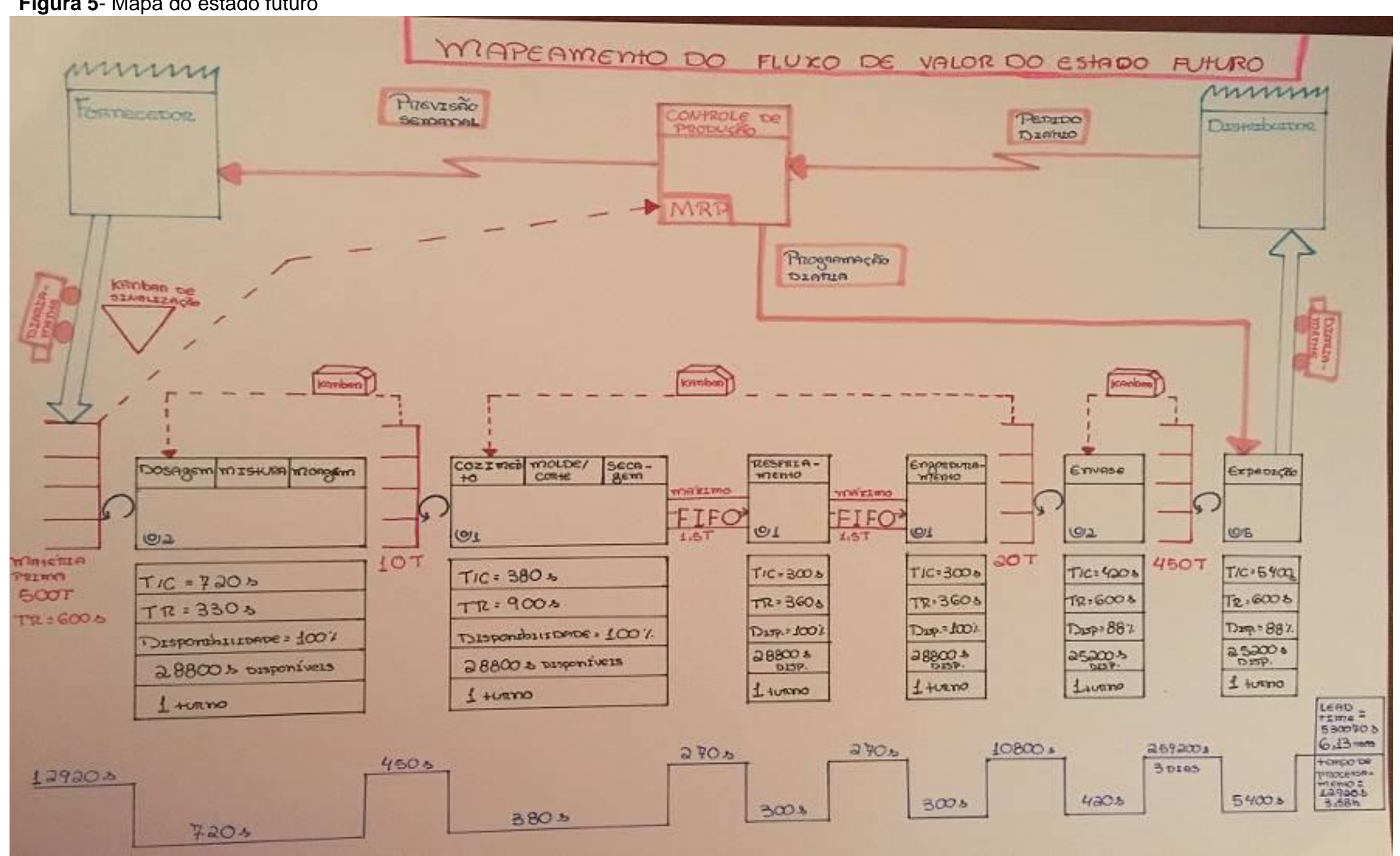

Fonte: Elaborado pelos autores 


\section{RESULTADOS E DISCUSSÕES}

Segundo Rother e Shook (2003) o sistema produtivo deve ser sincronizado de acordo com o takt time. O takt time pode ser calculado ao dividir o "tempo de trabalho disponível por turno" pela " demanda do cliente por turno". Para a fabricação de produtos extrusado pet food, o cálculo do takt time, foi realizado ao dividir 28800 segundos pelas 90 toneladas, chegando ao valor de 320 segundos. Mesmo no mapa do estado futuro, os tempos de ciclo de alguns processos permanecem maior que o takt time de produção. Porém, o sistema de cartões Kanban e supermercados irá estabelecer a sincronia do processo puxado de produção mesmo que ainda existam alguns gargalos. A comparação entre os resultados obtidos em cada um dos mapas elaborados encontra-se na figura 6.

O tempo de processamento (12920 segundos ou 3,58 horas) manteve-se o mesmo tanto no mapa do estado atual como no futuro. Pois, os tempos de ciclo referentes a cada um dos processos produtivos, não podem sofrer alterações sem que ocorra interferência na qualidade do produto final. O tempo de troca (3750 segundos ou 1,042 horas) também foi mantido, porém nota-se que é excessivo. Observa-se a necessidade da aplicação de ferramentas para otimização do tempo de setup (como SMED) para aplicação em trabalhos futuros.

Ao implantar o fluxo contínuo e agrupar processos em uma mesma célula de produção, foi possível diminuir a quantidade de operadores necessários para conduzir os equipamentos. No mapa do estado atual, o total de operadores foi igual a 17. Com as melhorias implementadas no mapa do estado futuro, a quantidade de operadores necessários caiu para 12. Sendo assim, a mão de obra excessiva pode ser realocada para outro setor de fabricação que tenha carência para que desperdícios e ociosidades sejam eliminados no processo de fabricação dos produtos extrusados pet food.

A principal melhoria identificada foi a redução do lead time, o tempo de atravessamento de 1,5 toneladas de materiais. No mapa do estado atual o valor encontrado foi de 1198160 segundos ou 13,8 dias. No mapa do estado futuro esse valor caiu para 530070 segundos ou 6,13 dias. O que significa que no estado ideal de produção o tempo entre realizar um pedido e a entrega do produto final é igual a 6,13 dias. Desta forma, pode-se notar a importância de implantar o sistema puxado de 
produção conduzido pelo cartão Kanban, os supermercados em pontos estratégicos da fabricação e o fluxo contínuo em todos os processos possíveis. A adoção dessas melhorias no sistema produtivo possibilitou a diminuição nos tempos e nas quantidades de estocagem o que resultou em uma significativa redução no lead time.

Figura 6 - Comparação dos resultados

\begin{tabular}{|c|}
\hline Estado atual \\
\hline Lead time: \\
1198160 seg. \\
(13,8 dias) \\
\hline Tempo de processamento: 12920 \\
seg. \\
(3,58 horas) \\
\hline Tempo de troca: \\
3750 seg. \\
(1,042 horas) \\
\hline Operadores: \\
17 \\
\hline
\end{tabular}

\begin{tabular}{|c|c|}
\hline Takt time= & Estado futuro \\
\hline $\begin{array}{c}\text { (Tempo de trabalho disponível por turno) } \\
\text { (demanda do cliente por turno) }\end{array}$ & $\begin{array}{l}\text { Lead time: } \\
530070 \text { seg. } \\
\text { (6,13 dias) }\end{array}$ \\
\hline & $\begin{array}{c}\text { Tempo de processamento: } 12920 \\
\text { seg. } \\
(3,58 \text { horas }) \\
\end{array}$ \\
\hline Takt time $=320 \mathrm{seg}$ & $\begin{array}{l}\text { Tempo de troca: } \\
1620 \text { seg. } \\
(0,45 \mathrm{~h})\end{array}$ \\
\hline 90 toneladas & $\begin{array}{c}\text { Operadores: } \\
12\end{array}$ \\
\hline
\end{tabular}

Fonte: Elaborado pelos autores

\section{CONSIDERAÇÕES FINAIS}

O presente estudo teve como objetivo identificar oportunidades de melhoria no processo de fabricação de produtos extrusados pet food em uma organização de grande porte. Para isso, utilizou uma ferramenta da filosofia lean, denominada mapeamento do fluxo de valor (MFV). Para a aplicação da ferramenta e coleta de dados, percorreu-se todo o fluxo de valor desde a expedição final até a primeira operação, que é o recebimento. Para a medição dos tempos utilizou-se um cronômetro, desta forma todos os valores que constam nos mapas representam a realidade do processo produtivo. Além disso, todos os passos necessários para o desenho dos mapas foram concluídos com rigor, incluindo a elaboração de forma manual (sem o auxilio de um computador).

No mapa do estado atual, pode-se observar a ocorrência de 8 pontos de estocagem, a produção ocorrendo de forma empurrada (o MRP manda as ordens de produção para os processos de recebimento, dosagem, envase e expedição), os tempos de troca para limpeza e ajuste dos equipamentos são excessivos. Como resultado o lead time de produção atinge o valor de 13,8 dias. Pode-se observar que existe carência de melhorias ao processo produtivo.

A partir da análise do mapa do estado atual, foi elaborado o mapa do estado 
futuro. As melhorias propostas foram discutidas com o supervisor de produção, com a finalidade de que pudessem ser implantadas na prática e não meramente ilustrativas. Para sincronizar a produção e estabelecer o fluxo puxado, foi aplicado o sistema Kanban para coordenação de ordens e também o sistema de supermercados em pontos estratégicos em que o fluxo contínuo não é possível de ser implementado. Além disso, o sistema MRP apenas envia a ordem de produção para o ultimo processo, a expedição, que foi intitulado de "processo puxador".

Ao implantar as melhorias sugeridas no mapa do estado futuro pode-se observar alguns ganhos ao processo. Ocorreu a redução do número de operadores necessários ao processo produtivo, identificou-se que 12 seriam suficientes. 0 excesso de mão de obra representa desperdícios como ociosidade e também custos desnecessários. A principal melhoria foi a redução do lead time, que é igual a 6,13 dias no mapa do estado futuro. Sendo assim, o cliente final pode ser atendido com maior velocidade sem a necessidade de um estoque de produtos acabados excessivo.

Para realizar o trabalho foi necessário a contribuição dos funcionários da fábrica que auxiliaram no levantamento dos desperdícios do processo e dedicaram o seu tempo ao projeto acompanhando as visitas nas instalaçês e fornecendo todos os dados necessários para a realização da pesquisa. O envolvimento dos funcionários é um ponto positivo do trabalho, pois permitiu que as melhorias relatadas não sejam apenas ilustrativas, pois podem ser de fato implementadas. Porém, uma das dificuldades foi encontrar um consenso entre diversas opiniões sobre o processo e os pontos de melhoria para que houvesse consistência no projeto do mapa do estado futuro.

Por fim, o objetivo do presente estudo foi atingido. Porém, apresenta algumas limitações por não ter abordado a viabilidade econômica das melhorias sugeridas e também não houve comprovação com ferramentas de simulação, por exemplo. Fica como sugestões para pesquisas futuras, trabalhos relacionados a viabilidade da aplicação das melhorias e também realizar uma análise aprofundada dos tempos de troca ao utilizar ferramentas como o SMED, para a redução de tempos de setup.

\section{REFERÊNCIAS}

ASSOCIAÇÃO BRASILEIRA DA INDÚSTRIA DE PRODUTOS PARA ANIMAIS DE ESTIMAÇẨO - Abinpet. Mercado Pet Brasil: mais de três décadas de esforço. 2018. 
Disponível em: http://abinpet.org.br/download/abinpet folder 2018 d9.pdf. Acesso em: 26 jun. 2018.

CAUCHICK P. A. M.; FLEURY, A. C. C.; MELLO, C. H. P.; NAKANO, D. N.; TURRIONI, J. B.; LEE HO, L.; MORABITO, R. N.; MARTINS, R. A.; PUREZA, V. Metodologia de pesquisa em engenharia de produção e gestão de operações. 1 ed. Rio de Janeiro: Campus Elsevier, 2009.

EMILIANI, M. L. Lean behaviors. Management Decision, v. 36, n. 9, p. 615-631, 1998. http://dx.doi.org/10.1108/00251749810239504

EMILIANI, M. L.; STEC, D. J. Using value-stream maps to improve leadership. Leadership \& Organization Development Journal, v. 25, n. 8, p. 622-645,2004.

http://www.emeraldinsight.com/doi/10.1108/01437730410564979

FORNO, A. J. D.; PEREIRA, F. A.; FORCELLINI, F. A.; KIPPER, L. M. Value stream mapping: A study about the problems and challenges found in the literature from the past 15 years about application of Lean tools. International Journal of Advanced Manufacturing Technology, p. 779-790, 2014. https://doi.org/10.1007/s00170-014-5712-z

GARCIA, J. L.; MALDONADO, A. A. Just-in-time elements and benefits. Springer International Publishing Switzerland. 2016. Disponível em: https://books.google.com.br. Acesso em: 3 mar. 2017.

GATES,M. A brief history of comercial pet food. Feline Nutrition. 2008. Disponível em: http://feline-nutrition.org/features/a-brief-history-of-commercial-pet-food. Acesso em: 17 fev. 2017.

HAMMARBERG, M.; SUNDEN, J. Kanban in action. Manning Publications, 2014.

HEDLUND, F. N.; FORCELLINI, F. A. Mapa de fluxo de valor estendido a avaliação do desempenho energético em consumidores industriais: um estudo de caso brasileiro. Revista Produção Online. Florianópolis, SC, v. 18, n. 2, p. 691-712, 2018.

http://dx.doi.org/10.14488/1676-1901.v18i2.2954

HINES, P.; RICH, N.The Seven Value Stream Mapping Tools. International Journal of Operations and Production Management, p 17, 1997.

https://doi.org/10.1108/01443579710157989

KEYTE, B.; LOCHER, D.The complete lean enterprise: value streams mapping for administrative and office process. Productivity Press, New York, 2004.

LIKER, J. K. O modelo Toyota: 14 princípios de gestão do maior fabricante do mundo. Bookman Editora, 2005.

LIKER, J. K.; MEIER, D. O Modelo Toyota: manual de aplicação, um guia prático para a implementação dos 4Ps da Toyota. Porto Alegre: Bookman, 2007.

LIKER, J. K.; CONVIS, G. L.The Toyota way to lean leadership: achieving and sustaining excellence through leadership development. Mc graw hill, p. 22, 2012.

LIMA, D. F. S.; ALCANTARA, P. G. F.; SANTOS, L. C.; SILVA, L. M. F.; SILVA, R. M. Mapeamento do fluxo de valor e simulação para implementação de práticas lean em uma 
empresa calçadista. Revista Produção Online, Florianópolis, SC, v. 16, n. 1, p. 366-392, 2016. https://doi.org/10.14488/1676-1901.v16i1.2183

MAZON, M. S., MOURA, W.G. Cachorros e humanos: mercado de rações pet em perspectiva sociológica, 2016.

OHNO, T. O Sistema Toyota de produção: além da produção em larga escala. Porto Alegre: Bookman, 1997.

POKSINSKA, B.; SWARTLING, D.; DROTZ, E. The daily work of lean leaders: lessons from manufacturing and healthcare. Total Quality Management \& Business Excellence. p. 886898, 2013. https://doi.org/10.1080/14783363.2013.791098

ROTHER, M.; SHOOK, J. Aprendendo a enxergar: mapeando o fluxo de valor para agregar valor e eliminar o desperdício. São Paulo: The lean enterprise institute, 2003.

SAGAWA, J. K.; DELAI, I. ; PEREIRA, N. A. . Sistemas de produção: uma abordagem estratégica. 1. ed. São Paulo: Pixel, v. 1. 62 p, 2015.

SINGH, B; GARG, K.; SHARMA, S. K. Value stream mapping: literature review and implications for Indian industry. The International Journal of Advanced Manufacturing Technology, v. 53, n. 5-8, p. 799-809, 2010. https://doi.org/10.1007/s00170-010-2860-7

SILVA, C., REIS, V., MORAIS, A., BRILENKOV, I., VAZA, J., PINHEIRO, T., NEVES, M., (...), CARMO-SILVA, S. A comparison of production control systems in a flexible flow shop. Procedia Manufacturing. 13, pp. 1090-1095, 2017.

https://doi.org/10.1016/i.promfg.2017.09.169

WARD, A.; SOBEK, D. Lean product and process development. The lean enterprise institute, Cambridge, MA, USA, ed 2, 2014.

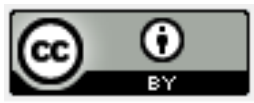

Artigo recebido em:19/11/2018 e aceito para publicação em: 01/12/2019

DOI:http://dx.doi.org/10.14488/1676-1901.v19i4.3458 